and transient swelling of face, body, and limbs (1); hypopyon of left eye (1); acute monarticular arthritis (1); and sulphonamide crystalluria (1).

Of the 12 meningococcal isolates obtained so far only one has shown sulphonamide resistance employing standard disc diffusion methods. Three of the four most recent strains have been found to be group I meningococci, the fourth belonging to group C. The minimum inhibitory concentration of the group B strains to sodium sulphadiazine was $1.6 \mu \mathrm{g} / \mathrm{ml}$, and in two of them it was $0.4 \mu \mathrm{g} / \mathrm{ml}$ to benzylpenicillin. Followup studies on six patients (including four infants less than 1 year of age) 4-10 weeks after discharge showed no evidence of residual damage.-We are, etc.,

L. M. DE SILVA Public Health Laboratory, Middlesbrough

B. M. MUHAMMAD K. DEVADAS Middlesbrough General Hospital, Middlesbrough

Gonorrhoea in Obstetrics and Gynaecology

SIR,-Gonorrhoea is still on the increase, with 18,341 postpubertal female cases in 1972.1 From the low incidence reported from antenatal screening (the highest figure obtained by British investigators being only $0.6 \%{ }^{2}$ ) and the screening of gynaecological patients $^{34}$ it is easy to conclude that gonorrhoea is not a problem in obstetrics and gynaecology in Britain, but caution is required, especially in gynaecological patients. Many units still erroneously rely on a high vaginal swab for diagnosis, which may or may not be placed in Stuart's transport medium before plating is possible. The most effective means of diagnosis is to take samples from the cervix and urethra and plate them at the bedside on to prewarmed selective gonococcal medium, ${ }^{5}$ the cultures being immediately placed in an incubator with a carbon dioxide-enriched atmosphere. At the same time Gram-stained smears are made from further samples.

In the $6 \frac{1}{2}$ months between November 1973 and mid-May 197410 cases of gonococcal salpingitis and one of gonococcal cervicitis have been found by this active approach in gynaecological patients. In six of these the Gram film gave immediate warning of the positive culture to come. It can be argued that it is immaterial to indentify the causative organism as antibiotics would be given anyway once a diagnosis of salpingitis has been reached. This is fallacious as it fails to identify the cases in which sexual contacts should be investigated by the venereology department.

No cases of Bartholin's abscess due to gonococcal infection were found during the same period. Most patients had already received antibiotics from their general practitioner so this is not surprising. It should be stressed that patients with a Bartholin's abscess should be admitted for surgical drainage and not treated first with antibiotics as they are ineffective and also confuse the bacteriological diagnosis.

Despite the screening of "at risk" antenatal patients, three cases of gonocoocal ophthalmia neonatorum were found between September 1972 and September 1973. The mothers were confirmed as having gonorrhoea. One disturbing feature is that the conjunctivitis developed between the sixth and ninth days after delivery. With the now common practice of early discharge after delivery in most obstetric units it is easy to miss the diagnosis unless the district midwife and general practitioner are alert to the possibility of a gonococcal cause.

In a recent circular the Royal College of Obstetricians and Gynaecologists recommends trainees in obstetrics and gynaecology to consider a post in venereology as part of the elective year. This would be beneficial in developing an insight into the problems of gonorrhoea detection and control.-I am, etc.,

R. A. SPARKS

St. David's and Llandough Hospitals,

1 Chief Medical Officer, Department of Health and Social Security, Britist

2 Rees, D. A., and Hamlett, J. D., fournal of Obstetrics and Gynaecology of the British Commonwealth, 1972, 79, 344 .
Hughes, W. M., and Davies, J. M., British Medical fourmal, 1971, 4, 424.

4 Silverston, P I., Snodgrass, C. A., and Wigfield, A. S., British fournal of Venereal Diseases, 1974, 50, 53.

Thaye, J. D., and Martin, J. E., jun., Public
Health Reports, 1966, 81, 559.

\section{Haemophilus influenzae Meningitis in} Adults

SIR,-So far as I know, the interesting report by Dr. Susannah J. Eykyn and others (1 June, p. 463) is unprecedented in that half of their cases of haemophilus meningitis occurred in adults. Could this distribution be related to the location of St. Thomas's Hospital? The population of that area, particularly during the working day, must contain an exceptionally large preponderance of adults.

Dr. Eykyn and her colleagues comment several times on the diffioulty of identifying $H$. influenzae in the Gram-stained deposit of cerebrospinal fluid. I should like once again to draw attention to the value of a good typing serum for $H$. influenzae type $\mathrm{b}$ in this situation. Typing is not mentioned in Dr. Eykyn's paper, but as your leading article (p. 462) pointed out capsulated strains of type $b$ are responsible for the great majority of cases of haemophilus meningitis. The practical relevance of this is that a capsuleswelling test with a good type b antiserum (such as that made by Hyland Laboratories) makes possible the firm identification of type b $H$. influenzae in C.S.F., even if they are few in numbers, within minutes of the arrival of the specimen in the laboratory. ${ }^{1}$

Your leading article was a joy to read and I am sorry to have to point out any fault in it; indeed, the fault lies not in the article but in its title. It dealt not with "Haemophilus influenzae infections" but with one group of such infections, making no reference, for example, to the activities of noncapsulated strains in the bronchi, which acoount for the great majority of $H$. influenzae infections in Britain.- I am, etc., Department of Bacteriology,
Radcliffe Infirmary,

D. C. TURK

1 Turk, D. C., and May, J. R., Haemophilus influenzae. Its Clinical Importance, pp. 35 and
120. London, English Universities Press, 1967.

\section{Interaction of Nalidixic Acid and Warfarin}

SIR,-It has been demonstrated in vitro that nalidixic acid can displace warfarin from binding sites on plasma proteins. ${ }^{1}$ This does not appear to be significant clinically. ${ }^{2} \mathrm{Dr}$. J. C. Petrie and his colleagues (4 May, p. 262 ) in their interesting study of the awareness of selected drug interactions go so far as to call the nalidixic acid-warfarin interaction "theoretical." The following case suggests that nalidixic acid given to patients stabilized on warfarin can produce potentially dangerous excess antiooagulation and should be avoided.

A 55-year-old woman was knocked down by a car in March 1972 fracturing her pelvis and left femur. This was followed by a left ileofemoral venous thrombosis, venous gangrene of the toes, and acute renal failure requiring peritoneal dialysis over a period of ver a period of several weeks. Her anticoagulation with warfarin was maintained after discharge and was well controlled with a prothrombin ratio around 2.0 on $11 \mathrm{mg} /$ day. The ratio was satisfactory on 20 December. She then developed Escherichia coli urinary infection and was given nalidixic acid $500 \mathrm{mg}$ four times daily by her family doctor on 8 January 1973. She was readmitted to hospital on 14 January with a purpuric rash on her abdomen and bruises on her left leg and back, which came on a few days after starting nalidixic acid. Her prothrombin time was 45 seconds (control 13). The platelet count was normal. Both drugs were discontinued. She was later discharged well with a prothrombin time of 22 seconds on $10 \mathrm{mg}$ of warfarin daily.

-I am, etc., Whittington Hospital,

B. I. HOFFBRAND

1 Sellers, E. M., and Koch-Weser, J., Clinical 2 Shith, S. E., and Rawlins, M. D., Variability in Human Drug Response. London, Butterworths, 1973.

\section{Antibacterial Preparations in the B.N.F.}

SIR,-The section of the new edition of the British National Formulary 1 dealing with "Drugs Acting on Infections: Antibacterial Preparations" contains a number of statements which might be challenged. Some of these are listed below.

(1) Carbenicillin. It is advised that for systemic infections this be given by continuous intravenous infusion. The data sheet issued by the makers advises that carbenicillin be given intravenously either by bolus injection or rapid infusion on the grounds that infusion over longer periods may result in subtherapeutic concentrations. Whatever the relative therapeutic merits of intermittent versus continuous administration, one is left with the other potential drawback of continuous infusion of the penicillins - that is, their possible inactivation by other components of the intravenous solution or incompatibility with other additives, notably gentamicin in the case of carbenicillin. This is not mentioned by the B.N.F.

(2) Ampicillin. Amoxycillin and its better absorption by the oral route should have been mentioned in a volume published in 1973.

(3) Gentamicin. This is said usually to have "a slightly wider margin of safety" than kanamycin. In fact the margin between therapeutically active and toxic serum levels is greater with kanamycin. ${ }^{2}$ For some reason the intravenous use of gentamicin is vetoed, though this mode of administration must be widespread for serious systemic infections, notably with Pseudomonas aeruginosa. 